\title{
AN INTEGRATED APPROACH FOR THE PREDICTION OF WATER QUALITY INDEX BASED ON LAND USE ATTRIBUTES USING DATA GENERATION METHOD AND BACK PROPAGATION NETWORK ALGORITHM
}

\author{
Faris Gorashi ${ }^{1}$ and Alias Abdullah ${ }^{2}$ \\ Kullivyah of Architecture and Environmental Design \\ INTERNATIONAL ISLAMIC UNIVERSITY MALA YSIA
}

\begin{abstract}
Malaysian experts have warned that several major cities, including the capital Kuala Lumpur, could face serious water shortages due to over-pollution of the country's rivers by problems brought about by over-development. As 97 per cent of Malaysia's water supply is sourced from surface water, the main aim of this study was to identify a relationship between water quality and land use attributes. The study which was conducted on Gombak River and its watershed in Malaysia, introduced data generation method for the prediction and forecast of LU/LC data within the watershed. The method used exponential model equation, Lagrange model equation third \& fourth degree polynomial fit; saturation growth-rate model in order to generate the required data; and artificial neural network's back propagation network algorithm. The study also introduces the LA-WQI model. This model was developed by associating the appropriate loading factors to a set of sub indices. The findings revealed that as the activities increased throughout the watershed, the values of WQI quality decreased accordingly. The accuracy of prediction of the proposed LA-WQI ranged from $94.3 \%$ to 99.3\% between Actual DOE-WQI and LA-WQI for station 18 in Gombak River. The results of predicted WQI obtained using LA-WQI, showed a continuous decrease of water quality. Despite the high accuracy attained by the application of LA-WQI model on Gombak River; it has not yet been tested on other rivers. It is recommended that future studies should be able to further test the current model on a regional scale.
\end{abstract}

Keywords: Water Quality Index, ANN, Gombak River, Back Propagation, Land-Use Data Generation

1 Ph.D./Doctoral Student, Kulliyyah of Architecture and Environmental Design (KAED), International Islamic University Malaysia (Email: dr.faris@gmail.com)

2 Professor, Department of Urban and Regional Planning, Kulliyyah of Architecture and Environmental Design (KAED), International Islamic University Malaysia (Email: profdralias@gmail.com / dralias@iiu.edu.my). 


\section{INTRODUCTION}

In Malaysia there are 189 river basins nationwide. Out of 189 river basins, 120 rivers are being monitored by the Department of Environment (DOE). There are 926 monitoring stations for these rivers. According to the Department of Environment ( $44.5 \%$ are clean, $48.4 \%$ slightly polluted and $7.1 \%$ are polluted. Generally, stations located upstream are clean, while those located downstream are either polluted or slightly polluted. The main cause of pollution of these river basins is over-development on the rivers' catchment area. The growth of urban areas has led to many problems, and any attempt to plan and manage the urban environment will ultimately have to be concerned with the entire city system and its interdependence with its rural hinterland, other city systems and the outside world as a whole. A prime goal of planning is to achieve efficiency in the utilization of resources with the objective of creating a high level of environmental quality for healthy living. Where urbanization is unstoppable and useful most of the time, the best management practices (BMP) serves to match both the necessity of mankind to innovate and high level of environmental quality. Some of the essential factors for BMP are shown in Figure 1.

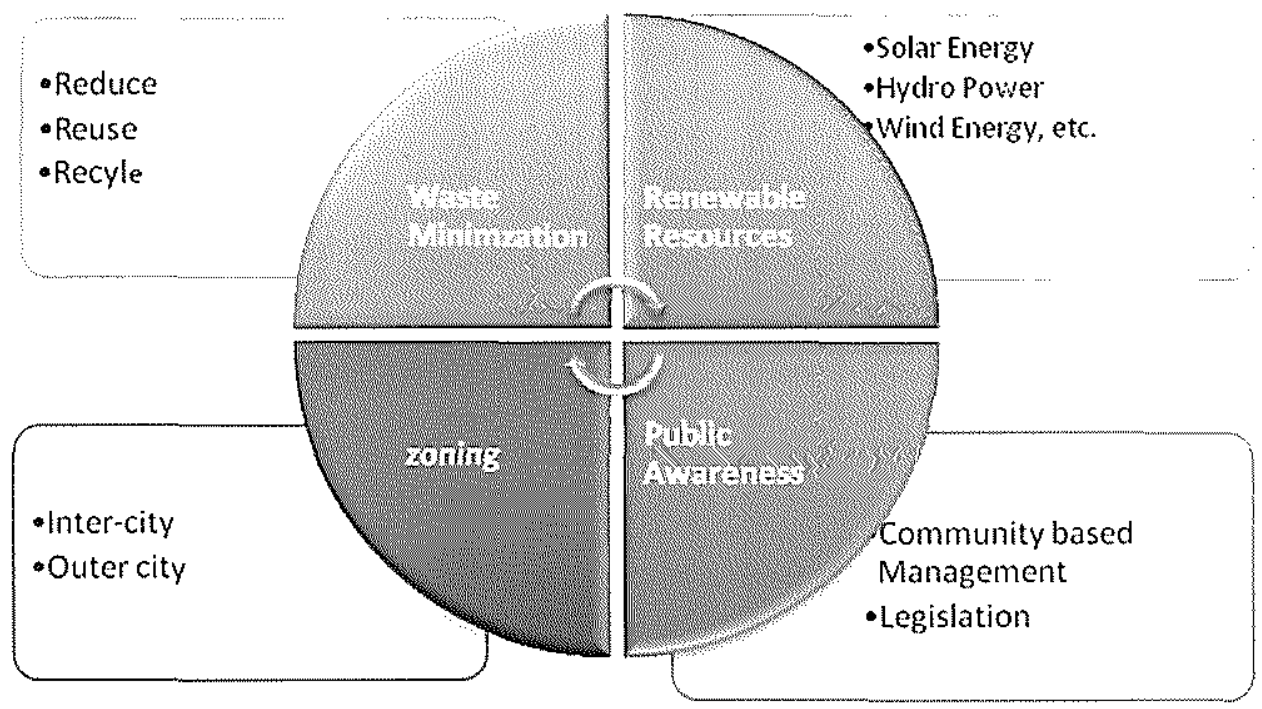

Figure 1: Suggested factors for improving best management practice in town planning 
These factors constitute a necessary condition, but alone it is not enough. Usually decisions made at the upper level of the decision hierarchy, significantly change the land use zoning patterns ${ }^{3}$. Rapid development in peninsular Malaysia has begun to put a strain on existing water resources. Environmental problems such as flash floods and heavy sedimentation are often associated with development activities within the basin. Water pollution also arises due to intensive land clearing, uncontrolled earthworks, mining and logging activities in water catchments area. The state of Selangor can be considered as one of the fastest developing states in Malaysia. Rapid development is one of the major reasons in causing water pollution.

\section{RELATED WORK}

The study of the relationship between water quality and urbanization is not new. Wang $(2001)^{4}$ examined how the form and rate of urbanization influence water quality through examining the effect of density and industrial activities on a range of water quality classifications. Work in Evans \& Miller (1988) ${ }^{5}$ provided an examination of the spatial variation to water quality across an entire watershed. The findings of researches reveal a strong relationship between the degradation of water quality and urban land use. While a number of studies (Goodchild \& Stevaert, 1993) ${ }^{6}$, (Engel et al., 1993) ${ }^{7}$, (Carr \& Chamber, 1998) ${ }^{8}$,

${ }^{3}$ Alias Abdullah, Kazuhisa IKI and Morozumi Mitsuo, 1994. A study to evaluate change of zoning in GIS operation due to the diversification of the AHP judgment, Proceeding of the Sixteenth Symposium on Computer Technology of Information, System and Applications, AIJ, S-5-6, pp. 349-354.

${ }^{4}$ Wang X., 2001. Integrating Water-Quality Management and Landuse Planning in a Watershed Context, Journal of envirommental management, 61, pp. 25-36.

${ }^{5}$ Evans, B. M. and D. A. Miller, 1988. Modeling Nonpoint Pollution at the Watershed Level with the Aid of a Geographic Information System, In Nonpoint Pollution: 1988 Policy, Economy, Management, and Appropriate Technology, American Water Resources Association, pp. 283-290.

${ }^{6}$ Goodchild, M. F., B. O. Parks, and L. T. Steyaert, (eds.) 1993. Geographic Information Systems and Environmental Modeling, Oxford University Press, New York, pp. 231237.

${ }^{7}$ Engel, B. R., R. Srinivasan, J. Arnold, C. Rewerts, and S. J. Brown, 1993. Nonpoint Source (NPS) Pollution Modeling Using Models Integrated with Geographic Information Systems (GIS). Water Science and Technology, Vol. 28, No. 3-5, pp. 685690 .

${ }^{8}$ Carr, G.M. and P.A. Chambers, 1998. Spatial and temporal patterns of nutrients and algal abundance in Alberta rivers. Report prepared for the Prairie Provinces Water Board, Regina, SK. 
(Corell et al., 2001) ${ }^{9}$ and (Tong \& Chen, 2002) ${ }^{10}$ concluded that land use has a direct effect on the deterioration of water quality of rivers through point and non-point effluent discharges, few have dealt specifically with the relationship that defines this relationship. Generally, river systems are polluted by point and non-point sources. Currently, there are very little efforts directed towards monitoring non-point sources in Malaysia. Monitoring of all point and nonpoint is very difficult or impossible to achieve; whereas the procedure is costly, time consuming and needs a large body of manpower. Thus the need for indirect approaches has grown widely in the recent years. In order to obtain an accurate assessment of spatial and temporal variation of land use, using water quality as a key indicator, many studies of modeling using different approaches has been attempted in recent years. Hubert-Moy et al." used Dempster-Shafer theory of evidence to predict land use and land cover, however the differences between prediction and reality were associated with uncertainties which is of great interest to the expert. Non predicted changes were due to unexpected transformation of land use. Generally, the model produced was unable to eliminate the anomalies associated with the prediction. In a later research. (Smith et al., 2003) $^{12}$ developed an approach using LandSat imagery, trained with high resolution data sets. These data sets identified the impervious surface area at sub-pixel resolution. The data were then used in a time series spatial predictive model using Monte Carlo's approach. The model simulated urbanization in four ways, as edge growth, spreading urban centers, road induced growth and spontaneous growth. The first look of the results taken from this model shows good monitoring techniques used, however the prediction model is limited to the probabilistic categorization and assumptions initiated by the author.

${ }^{9}$ Correll, D.L., Jordan, T.E.. and D.E. Weller. 2001. Effects of precipitation, air temperature, and land use on organic carbon discharges from Rhode River watersheds. Water, Air and Soil Pollution, 128, pp.139-159.

${ }^{10}$ Tong, S. T. Y. and W. Chen. 2002. Modeling the relationship between land use and surface water quality, Joumal of Environmental Management, 66, pp. 377-393.

"Hubert-Moy, L.. Cotonnec, A.. Le Du, L., Chardin, A.. and Perez, P. (eds), 2001. A Comparison of Classification Procedures of Remote Sensed Data Applied on Different Landscape Units, Remote Sensing of the Environment, Elsevier, Vol. 75, No. 2, pp. 174187.

${ }^{12}$ Smith, A. J., Goetz, S.D., Prince, R. and Wright, B., 2003. Estimation of sub-pixel impervious surface area using a decision tree approach, Remote Sensing of The Environment, (in press). 
W. Ren et al. (2003) ${ }^{13}$ examined the water quality of Huangpu River in China, and land use of the same river watershed, their study revealed the correspondence of deterioration of water quality with respect to the rapid urbanization. The authors took a period of 50 years to analyze their data, and concluded that there is a strong indication of influence of the industrial land use on the changing of the water quality of the river. However the type and nature of industrial activities, changing technologies and the factors affecting the water quality were not explored in their study. In another study, Noorazuan et al. $(2003)^{1+4}$ applied GIS in evaluating the change in land use and its impact on the stream flow of Langat River in Malaysia. The study revealed the landscape diversity of Langat significantly altered the Langat's stream flow response. Although the study has given acceptable results of the change of stream flow which was $20.35 \%$ in $1983-1988$ to about 31.4 in $1988-1994$, the stream flow and characteristics were not included within the study scope.

Based on the complexity of the alteration of water quality, simulation Models have always been good practice to simulate real-time situations with controlled variables; However for water quality response the behavior of water quality characteristics changes is a non-linear one. Kadri, et al. (2004) ${ }^{15}$ attempted a stochastically based approach model in order to predict daily maximum stream flow. Stochastic models can be used to predict water quality as well, but most of the conventional statistical models are based on the assumption that the observations are independently distributed in time. The occurrence of the event is assumed to be independent of all previous events. This assumption is not always valid for hydrologic time series. Chandra $(2003)^{16}$ used mass budget regression model in order to extract percentages of pollutants from point and non-point sources from the upstream to the downstream of Krishna River in India. Although the recent development on regression models for the prediction of pollutant loads can give more acceptable results, such models could only be useful in predicting the physical water

\footnotetext{
${ }^{13}$ Wenwei Ren, Yang Zhong, John Meligrana, Bruce Anderson, W. Edgar Watt, Jiakuan Chen, and Hok-Lin Leung, 2003. Urbanization, Land use, and Water Quality in Shanghai, Environment International, 29, Elsevier, pp. 649-659.

${ }^{14}$ Noorazuan M. H, Ruslan Rainis, Hafizan Huahir, Sharifuddin, M. Zain, and Nazari Jaafar, 2003. GIS Application in Evaluating Land use - Land Cover Change and its Impact on the Hydrological Regime in Langat River Basin, Malaysia, Map Asia Conference 2003. GISdevelopment.net.

${ }^{15} \mathrm{Kadri}$, Yurekli, Ahmet Kurunc, and Huseyin Simsek, 2004. Prediction of daily Stream Flow Based on Stochastic Approaches, Journal of Spatial Hydrology, Vol. 4, No. 2.

${ }^{16}$ Sekhar M. Chandra, and Sreenivasulu, 2003. Modeling Nutrients Contributed by Overland Flow From the Krishna River Basin, Diffise Pollution Conference, Dublin, Water Resources Management, 1A, pp. $20-23$.
} 
quality parameters. Other pollutants such as constituents that undergo chemical transformation, alteration, degradation and / or volatilization cannot be assessed using this approach as it will not give accurate segments unless the distance between the upstream and the downstream is negligible, which is impossible in practice.

The same author (Chandra, 1995) ${ }^{17}$ had attempted earlier modeling of land use and water quality. In his study the author focused on the cause-effect principal. Using the mass budget from non-point sources discharges compared to existing land use. The results were concluded as percentage output. Theoretically this method could give good results in a controlled environment; however the application of this model on surface water could give a very false statuesque. This approach is an indicative one and needs more development. Most of land use change studies have mainly dealt with the analysis and modeling of land use change ${ }^{8}$. Simulation models had always been good practices to model a real time situation with controlled variables, however, due to the complexity of water response/behavior in rivers, analysis of data recorded or generated, suffer to understand this complexity. In a study on recreational zoning development, Alias et al., (1994) ${ }^{19}$ concluded that zoning map and policy can be effectively developed through a quantitative spatial analysis.

In recent years, geographic information systems (GIS), artificial neural network (ANN) and fuzzy logic techniques have been used in several hydrological studies. However, few of these research studies have undertaken an extensive sensitivity analysis (Dixon, 2004) ${ }^{20}$.

\footnotetext{
${ }^{17}$ Sekhar, M. Chandra, and P. Anand. Raj, 1995. Land Use Water Quality Modeling, Joumal Of Water Science Technology, Vol. 31, No. 8, IWA Publishing, pp.383-386.

${ }^{18}$ Ruslan Rainis, 2003. Application of GIS and Landscape Metrics in Monitoring Urban Land Use Change, "Urban Ecosystem Studies in Malaysia. A Study of Change", Noorazuan Md Hashim \& Ruslan Rainis (eds.), Universal Publishers, pp 267 -278.

${ }^{19}$ Alias Abdullah, Kazuhisa IKI and Mitsuo Morozumi, 1994. An integrated approach of AHP and GIS application to analyze and develop recreational zoning, Joumal of Architecture Planning and Environmental Engineering, AIJ, No. 463, pp. 213 - 222.

${ }^{20}$ Dixon, B., 2004. Applicability of Neuro-Fuzzy Techniques In Predicting Ground Water Vulnerability: A GIS-based sensitivity analysis, Journal of Hydrology, published by Elsevier B. V. doi:10.1016/jhydrol.2004.11.010. Retrieved online on 22/04/2005. http:/www.sciencedirect.com
} 


\section{Artificial Neural Network (ANN)}

The concept of artificial neurons was first introduced in 1943. Artificial Neural Network is a network of interconnected elements. These elements were inspired from studies to simulate the biological brain. The purpose of Artificial Neural Network is to learn to recognize patterns in ones data. Once the Neural Network has been trained on samples of data, it can make predictions by detecting similar patterns in future data ((Cormac, 1999) $)^{21}$ and (Picton, 1994) ${ }^{22}$ ). Mostly used neural networks are SFAM algorithm, where one attempts to predict the class or category for a given pattern. The architecture of the network was better explained in a previous study by the authors ${ }^{23}$. Other widely used neural network is the Back Propagation Neural Networks and sometimes called Feedback Network. This method can predict the variable quantity with high precision, for example the concentration of a certain parameter. The algorithm makes its prediction as numeric values, not as class names. It is best suited for predicting continuous numerical values such as water quality data.

Training an ANN is a mathematical exercise that optimizes all of the ANN's weight and threshold values using some fractions of the available data. Neural networks serve to provide researchers with empirical models of complex system from which they can begin to unravel the underlying relationships and come to a more complete understanding of the environment. The most commonly used activation function within the nodes is the logistic sigmoid function, which produces output in the range of $0-1$ and introduces nonlinearity into the network, which gives the power to capture non-linear relationships between input and output values. The logistic function was used in this work in the form given below.

$$
H_{s} y=\frac{1}{1+s^{-x}}
$$

While many statistical and empirical models exist for water quality prediction, artificial neural network (ANN) models are increasingly being used

\footnotetext{
${ }^{21}$ Cormac Technologies Inc., 1999. Mamual, NeuNet Pro, Revision 2.2. Cormac Technologies Inc. (http://www.cormactech.com/Neunet)

${ }^{22}$ Picton, P. D., 1994. Introduction to neural network, The Macmillan Press Ltd: London.

${ }^{23}$ Faris, F.G. \& Alias A., 2008. A Study on the Water Quality of Gombak River Using Artificial Neural Network, Al-Rissala Journal, International Islamic University Malaysia (In press).
} 
for forecasting of water resources variables because ANNs are often capable of modeling complex systems for which behavioral rules are either unknown or difficult to simulate. Hafizan et al., (2004) ${ }^{24}$ mentioned "previous studies have shown that ANN models perform well in predicting short and long-term environmental data". Loke et al., (1997) ${ }^{25}$ concluded that ANNs can deal with problems that are traditionally difficult for conventional modeling techniques to solve. In recent years, artificial neural networks were successfully applied in the area of water quality modeling. The use of ANN model was to be better than other simulations and commonly used statistical models ${ }^{26}$ due to the complex inter-related and non-linear relationships between multiple parameters. However, modeling applications for water quality response due to land use attributes are generally more difficult due to the complexities in environmental distribution, mobility and number of point and non-point sources of waste discharge.

Junaidah et al., (2004) ${ }^{27}$ concluded that the model derived using MLR technique gave a better prediction than the model derived using ANN in a study on sediment prediction, However, this statement can be debatable depending on the complexity of the model itself. Water quality responds to myriad stimuli and reactions. Many chemical constituents are involved either naturally or synthetically. The model of which cannot be treated in a linear manner. ANN is intended to be used with problem of complexity. A later study by Stewart ${ }^{28}$

${ }^{24}$ Hafizan Juahir, Sharifuddin M. Zain, Zainal Ahmad, Nazari M. Jaafar, 2004. An Application of Second Order Neural Network Back Propagation Method in Modeling River Discharge. In Water Environmental Planning: Towards Integrated Planning and Management of Water Resources for Environmental Risks, Alias Abdullah, Norio Okada, and Mohd Kamil Yusoff, eds., International Islamic University Malaysia, pp. $307-324$.

${ }^{25}$ Loke, E.. Warnaars E. A., Jacobsen P., Nelen F. and Ceu Almeida M., 1997. Artificial Neural Networks as a tool in Urban Storm Drainage, Jounal of Water Science and Technology, Vol. 36, Issues 8-9, pp. 101-109.

${ }^{26}$ Diane M. L., David P. A., 2004. Use of Artificial Neural Network Models to Predict Indicator Organisms Concentrations in an Urban Watershed, AGU, 85(17), Joint Assembly Suppl., Abstract H53A-06 1330h POSTER.

${ }^{27}$ Junaida Ariffin, Aminuddin Abdul Ghani, Nor Azazi Zakaria, and Ahmad Shukri Yahya, 2004. Sediment Prediction Using ANN and Regression Approach, Proceedings of the $1^{\text {st }}$ International Conference on Managing Rivers in the $21^{\text {st }}$ Century: Issues \& Chanlenges, Malaysia, pp. 168-174.

${ }^{28}$ Stewart A. Rounds, 2002. Development of a Neural Network Model for Dissolved Oxygen in the Tualatin River, Oregon, Proceeding of the second Federal Interagency Hydrologic Modeling Conference, Las Vegas, Nevada, July 29 - August 1, 2002 Subcommittee on Hydrology of the interagency Advisory Committee on Water Resources. 
revealed that a multiple linear regression may be viewed as a special case ANN model that uses linear transfer functions and no hidden layers. If the linear model performs as well as a more complex ANN, then using the nonlinear ANN may not be justified; however the optimization of the ANN model revealed a markedly better prediction than the MLR model in a study to predict the concentration of dissolved oxygen in a river. In addition multiple linear regression models failed to capture the long term patterns; however ANN model was successful in predicting those patterns (Zou et al., 2002) ${ }^{29}$.

A study done by Kamarul and Ruslan $(2004)^{30}$ concluded that ANN could become a useful modeling method, as alternative to actual data collection, thus is the best choice for the government to manage water resource issues. The study uses existing raw water quality data from official sources and related to eight land uses categories i.e. residential, industrial, commercial, public utilities, recreational, institutional, and forest. In this study the authors used the Simplified Fuzzy Adaptive Resonance Theory Map [SFAM]. The SFAM logic output was according to classes of water quality. Although the findings were well correlated, nevertheless, the wide range of water quality classes will not give an accurate forecast in terms of a particular water quality parameter. Using a different approach such as back propagation could have given more précised findings.

\section{CASE STUDY}

The study area of this research is Gombak River. Gombak River is situated mainly in the Gombak District in Selangor state and its lower zone is situated in the Malaysian Capital Kuala Lumpur. The River is a slow flowing one, which originates from many tributaries in the Gombak district. The river has several confluences with other streams such as Batu River, Untut River, and Kelang River in the Heart of Kuala Lumpur. Figure 2 shows a map of the Gombak River Catchment area. The catchment area within which the river passes through, has grown quite rapidly since early 1970 s and is expected to continue growing in the future. The topography of the watershed area, as it is surrounded

\footnotetext{
${ }^{29}$ Zou, R., Lung, W.S., and Guo, H., 2002, Neural Network Embedded Monte Carlo Approach for Water Quality Modeling Under Input Information Uncertainty, Journal of Computing in Civil Engineering, ASCE, 16 (2), pp. 135-142.

${ }^{30}$ Kamarul Ismail, and Ruslan Rainis, 2004. Modeling River Water Quality Index Using Artificial Neural Networks and Geographical Information System. In Water Environmental Planning: Towards Integrated Planning and Management of Water Resources for Environmental Risks, Alias Abdullah, Norio Okada, and Mohd Kamil Yusoff, eds., International Islamic University Malaysia, pp. 307-324.
} 
by hilly mountains. Gombak river watershed is in the upper part of Klang river basin. About $60 \%$ of the catchment is steep mountains rising to a height of $1220 \mathrm{~m}$. The Gombak River drains a narrow elongated watershed that runs slightly west of south from the steep-sloped main range mountains down through more gently sloping foothills to the alluvial plain in the vicinity of north Kuala Lumpur ${ }^{31}$. Sungai Keroh, Sungai Pusu, Sungai. Rumput, Sungai. Salak, Sungai. Semampus and Sungai. Blongkong feed Gombak River.

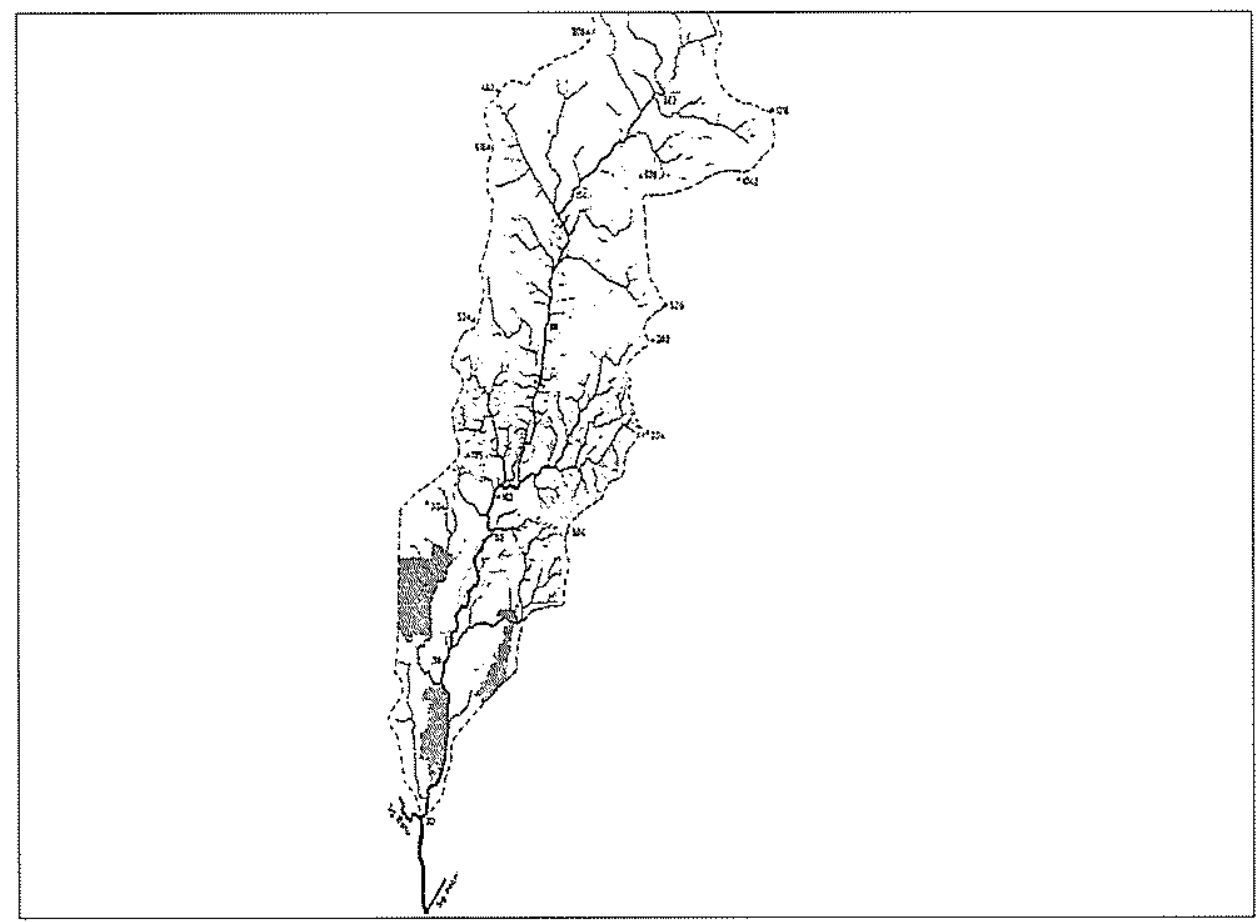

Figure 2: Map of Gombak River catchment area.

The Gombak River traverses a vast spectrum of land use change within the Gombak River watershed area. The axial length of the drainage basin is 22.2 $\mathrm{km}$, average width $5.5 \mathrm{~km}$, and an area of 123.3 square $\mathrm{km}$. The river confluence with Batu River at 28.3 metre altitude ${ }^{32}$ Gombak River and Kelang River meet at a confluence point in the heart of Kuala Lumpur city. The watershed can be divided into three main sections. The upper zone, including

${ }^{31}$ Bishop, J. E., 1973. Limnology of a Small Malayan River, Sungai Gombak, The Hague., pp. 485.

${ }^{32}$ Lai, F.S., 1983. Biochemical Oxygen Demand Concentration of Two River Basins of Selangor, Pertanika, Vol. 6(3), pp. 32-43. 
the upper tributary sub-zone, takes in the undisturbed forest reserve areas of the watershed and terminates at the point where the river leaves the steep sloped hills and enters the gentler foothill section. The middle and lower zones with gradients of $4.7 \%$ and $2.2 \%$ respectively.

\section{RESEARCH APPROACH}

A water index is a method of combining various water quality parameters into one concise and objective value representing the state of the water quality trends. The WQI (Water Quality Index) is used to compare water quality on rivers, on different locations on the same river, and to measure water quality changes over a period of time. There are many methods used for the calculation of WQI. The Department of Environment (DOE) has obtained an opinion-poll formula for the calculation of WQI. A panel of experts is consulted on the choice of parameters and on the weightage to be assigned to each parameter. The parameters, which have been selected, were: DO (Dissolved Oxygen), BOD (Biochemical Oxygen Demand), COD (Chemical Oxygen Demand), AN (Ammonia-Nitrogen), SS (Suspended Solids) and $\mathrm{pH}$ ( $\mathrm{pH}$ value). A more comprehensive description of the DOE-WQI and Harkins' method had been discussed in a previous study by Faris \& Alias, $(2008)^{33}$.

The water quality parameters are accessible and can be made available as frequent as needed; however, land use and land cover are difficult or impossible to obtain in short frequent terms. To overcome this challenge, it was deemed necessary to develop a method for data generation that can mimic the actual land use and land cover. The proposed method will be able to predict the actual data then and to project (forecast) data for the future. The generation of land use or land cover data is essential for the ANN training of the river based on land use sub indices and for building the model that predicts and forecasts the WQI of the river.

\section{Data Generation Models and Boundary Conditions for Gombak River Watershed}

For the purpose of this study and in order to generate land use or land cover data, the following models and boundary conditions will be followed:

${ }^{33}$ Faris, F.G. \& Alias Abdullah, 2008. Prediction of Water Quality Index Using Back Propagation Network Algorithm. Case Study: Gombak River, Journal of Engineering Science and Technology, 2008 (In press). 


$$
\text { Exponential Model Equation: } \quad y=a^{e^{b x}}
$$

Exponential model will be used to generate data for all ascending values. However if the values (according to the planner's decision) need to be stabilized based on maximum capacity of the watershed or the region, then another model (Lagarange Model) will be used in order to generate data for the converging values.

Lagrange Model Equation: 3rd degree Polynomial Fit: $y=a+b x+c x^{2}+d x^{3} \ldots \ldots$

Third degree polynomial model will be used in order to generate data that had reached the maximum capacity area allocated for the watershed/region. The data generation will continue until the value of the generated area reaches the capacity area.

In order to generate descending values such as forest area, the saturation growth model will be used.

\section{Saturation Growth-Rate Model: $\quad y=\frac{a x}{(b+x)}$}

The data will be generated until a convergent point has been reach. At this point the maximum allocated capacity of the category will be reached. After the land use or land cover data were generated. Another neural network was set up to train the stations 18 and 24 based on LU/LC parameters only. The configuration of the network was not changed to ensure the consistency of the training. The network used WQI values that corresponds the same date of the generated LU/LC data.

\section{The Proposed Land-Use Attributes WQI Model (LA-WOI Model)}

This model was developed by associating the appropriate loading factors to a set of sub indices. The loading factors were obtained based on peak factor theorem by assigning weights to different categories of land use indices. These weights were primarily assigned based on the effect of each land use as well as the existence of each category within the watershed. Then they were corrected furthermore by trial and error until the required weights were assigned.

The proposed model:

$$
\mathrm{LA}-\mathrm{WQI}=100-[0.15 \mathrm{BU} s i+0.17 \mathrm{R} s i+0.26 \mathrm{C} s i+0.38 \mathrm{I} s i+0.04 \mathrm{Fs} i]
$$


Where, BUsi is the build-up area sub index; build-up area represents the effluents of storm and wash water from the build-up area, Rsi is the residential area sub index, Csi is commercial area sub index, Isi is Industrial area sub index and Fsi is the Forest area sub index. It has been thought earlier, that forest area within a river watershed does not degrade the water quality of the river; However, Mohd Kamil et al. ${ }^{34}$ concluded in a study of water quality index and forest health, that a disturbed forest will degrade the water quality of the river within its catchments.

Assumptions and boundary conditions - The land use and activities within catchments area may vary from one river to another; however the main land uses and activities that constituted Gombak River catchment were the ones used as input parameters in the proposed model. These parameters were assumed to be the most effective ones after an extensive training process using the (leave-one-out) method. The input parameters represent the effluents discharged from each category and the physical area per se. The loading factors (associated weights) were obtained by ANN training and using peak factor theorem.

All the five categories are firstly generated as area measured in acres and converted to percentages of the watershed. These percentages are considered as the effects of these categories on water quality. They are then calculated using the logistic model and boundary conditions as shown on Table 1.

The calculation of the sub indices were based on the Logistic Model:

$$
f(x)=\frac{1}{1+e^{-x}}
$$

The reason for choosing the logistic model is that it is based on the sigmoid function, a function of which is used internally for the training of artificial neural networks' back propagation algorithm. The model will be applied on the average values of the percentages of land use every year, and will be compared with average values of yearly WQI (actual and ANN predicted). The predicted WQI will include both water quality and land use sub indices.

\footnotetext{
${ }^{34}$ Yusoff, M.K., Heng, S.S., Majid, N.M., Mokhtaruddin, A.M., Hanum, I.F., Alias, M.A., \& Kobayashi, S., 2001. Effects of different land use patterns on the stream water quality in Pasoh, Negeri Sembilan, Malaysia. In Rehabilitation of Degraded Tropical Forest Ecosystems: Workshop Proceedings, Kobayashi, S., Turnbull, J.W., Toma, T. Mori, T., Majid, N.M.N.A. eds., 2-4 November 1999, CIFOR, Bogor, Indonesia, pp. 8798.
} 
Faris Goroshi and Alias Abdullah

An Integrated Approach for the Prediction of Water Quality Index based on Land Use Atributes Using Data Generation Merhod and Back Propagation Network Algorithm

Table 1: Sub Index Equation and Boundary Conditions for the Proposed LA-WQI Model.

\begin{tabular}{|c|c|c|}
\hline $\begin{array}{l}\text { Parameter } \\
(\%)\end{array}$ & $\begin{array}{l}\text { Boundary } \\
\text { Conditions }\end{array}$ & Sub-Index (si) Equation \\
\hline \multirow{3}{*}{$\begin{array}{l}\text { Build up } \\
\text { Area }\end{array}$} & $x \leq 1$ & $\mathrm{BU} s i=0$ \\
\hline & If $\quad 1<X>88$ & BUsi $=\frac{a}{1-b x^{-2 x}} \quad$ where, $\begin{aligned} \mathrm{a} & =110.04386 \\
\mathrm{~b} & =14.002778 \\
\mathrm{c} & =0.054011454\end{aligned}$ \\
\hline & $x>88$ & $\mathrm{BU}$ si $=100$ \\
\hline \multirow{3}{*}{$\begin{array}{l}\text { Residential } \\
\text { Area }\end{array}$} & $X \leq 5$ & $\mathrm{Rs} i=0$ \\
\hline & If $\quad 5<x>55$ & 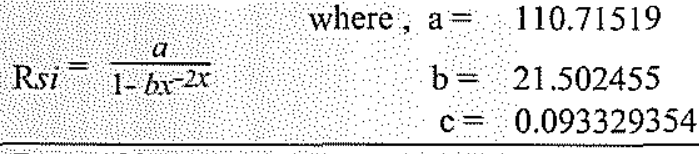 \\
\hline & $x>55$ & $\mathrm{Rsi}=100$ \\
\hline \multirow{3}{*}{$\begin{array}{l}\text { Commercial } \\
\text { Area }\end{array}$} & $X \leq 2$ & $\mathrm{Cs} i=0$ \\
\hline & If $\quad 2<X>50$ & $\begin{aligned} C s i=\frac{a}{1-b x^{-2 x}} \quad \text { where, } \quad \mathrm{a}= & 110.71522 \\
\mathrm{~b} & =16.378263 \\
\mathrm{c}= & 0.097218005\end{aligned}$ \\
\hline & $X>50$ & $\mathrm{Cs} i=100$ \\
\hline \multirow{3}{*}{$\begin{array}{l}\text { Industrial } \\
\text { Area }\end{array}$} & $X \leq 0.5$ & $1 s i=0$ \\
\hline & If $0.5<x>20$ & $\begin{array}{r}\text { where }, a=107.92071 \\
\qquad b=14.190819 \\
c=0.24676863\end{array}$ \\
\hline & $x>20$ & $\mathrm{Isl}=100$ \\
\hline \multirow{3}{*}{ Forest Area } & $x \leq 20$ & $F_{s i}=0$ \\
\hline & If $20<X>80$ & $\begin{aligned} \text { where, } & a=110.715 \\
& b=63.881014 \\
c & =0.077774785\end{aligned}$ \\
\hline & $X>80$ & $\mathrm{~F} s i=100$ \\
\hline
\end{tabular}




\section{RESULTS AND DISCUSSIONS}

The water quality index sums up the overall quality of the three stations located along the Gombak River. As shown in Figure 3, the mean WQI for stations 24, 18 and 17 respectively were 91,68 and 57 on the DOE WQI scale. This puts station 24 as clean river water; station 18 as slightly polluted and station 17 as polluted river water. Station 18 is considered the downstream of Gombak river watershed. The station was trained using ANN back propagation algorithm. The neural network was configured with 5 hidden nodes, 12125 iteration cycles and a momentum of 50 . The results of the network produced normalized RMS error of 0.86 and Actual error of 0.36 .

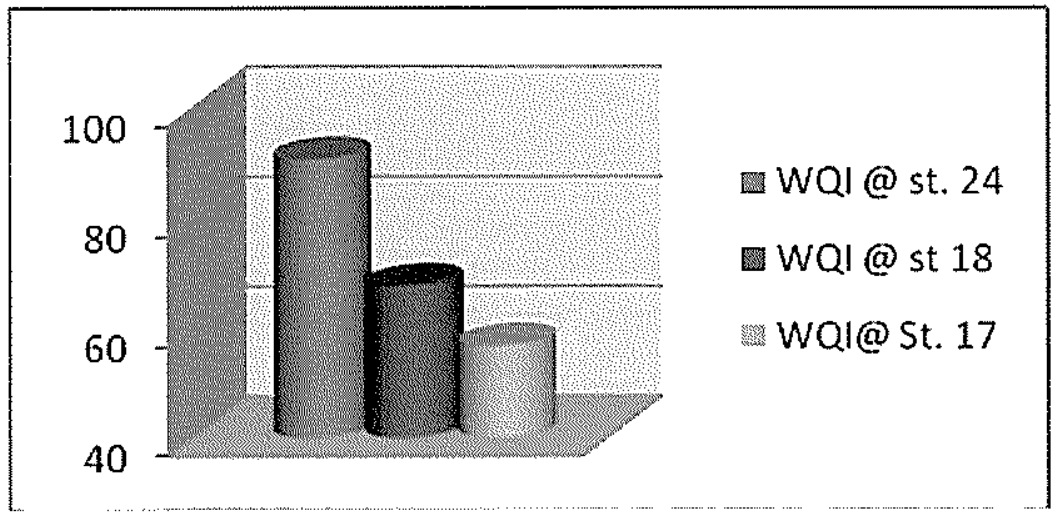

Figure 3: Average Annual Values of Gombak River for the period of 1999 to 2006.

The network later was able to produce its own minimum, maximum and mean values for predicted output. Based on the results (Please refer to Table 2) obtained by the network, back propagation algorithm was able to predict WQI with high accuracy. The number of tested WQI was equivalent to that of the predicted one. The time-series graph shown in Figure 4 indicates very high accuracy of prediction of WQI at station no. 18 of Gombak River. Values that appear less than the actual data is due to the learning process of the network. Water quality monitoring station no. 18 is the last monitoring point within the boundary of Gombak River watershed. Unlike station no. 24, the land use affecting the water quality of Gombak River is an extensive one as shown on Table 3 and Figure 5. The build-up area exceeds $80 \%$ of the total area of this part of the watershed. It is important to understand the evolution of land use within the watershed in order to generate data and to forecast data for future development. The build-up area increment has stabilized to a lesser value after the year 2000 as shown in Figure 6. This stabilization indicates that the capacity of the watershed has approached its peak. 
Faris Goroshi and Alias Abdulloh

An Integrated Approach for the Prediction of Water Quality Index based on Land Use Atributes Using Data Generution

Method and Back Propagation Neturork Algorithm

Table 2: Results of Actual vs. Predicted WQI using Back Propagation Algorithm of Station No. 18

\begin{tabular}{|c|c|c|c|c|c|}
\hline $\begin{array}{l}\text { Actual } \\
\text { WQI }\end{array}$ & $\begin{array}{c}\text { Predicted } \\
\text { WQI }\end{array}$ & $\begin{array}{l}\text { Actual } \\
\text { WQI }\end{array}$ & $\begin{array}{c}\text { Predicted } \\
\text { WQI }\end{array}$ & $\begin{array}{c}\text { Actual } \\
\text { WQI }\end{array}$ & $\begin{array}{l}\text { Predicted } \\
\text { WQI }\end{array}$ \\
\hline 85.88 & 84.95 & 61.41 & 61.25 & 65.51 & 65.29 \\
\hline 79.99 & 80.31 & 61.61 & 61.93 & 68.37 & 68.16 \\
\hline 45.88 & 47.04 & 62.91 & 62.57 & 77.28 & 77.10 \\
\hline 64.71 & 64.60 & 75.17 & 75.24 & 38.81 & 47.04 \\
\hline 55.19 & 55.07 & 62.09 & 62.07 & 63.06 & 63.15 \\
\hline 53.64 & 53.67 & 71.87 & 71.72 & 70.47 & 70.19 \\
\hline 58.46 & 58.43 & 81.16 & 80.58 & 65.58 & 65.58 \\
\hline 50.49 & 49.89 & 73.33 & 73.27 & 52.05 & 51.44 \\
\hline 78.84 & 78.71 & 69.00 & 68.81 & 71.19 & 70.96 \\
\hline 66.31 & 66.13 & 73.40 & 73.03 & 78.15 & 78.58 \\
\hline 67.00 & 66.76 & 66.38 & 66.19 & 73.32 & 72.79 \\
\hline 52.87 & 52.99 & 81.74 & 80.92 & 74.65 & 74.59 \\
\hline 57.40 & 57.36 & 77.43 & 77.06 & 75.74 & 75.66 \\
\hline 80.59 & 80.08 & 67.55 & 67.33 & 69.79 & 69.69 \\
\hline 52.73 & 52.74 & 65.59 & 65.38 & 71.75 & 71.96 \\
\hline 53.24 & 52.84 & 59.94 & 60.09 & 64.61 & 64.57 \\
\hline 77.93 & 77.79 & 66.24 & 65.98 & 64.97 & 64.91 \\
\hline 61.59 & 61.72 & 65.61 & 65.49 & 69.43 & 69.00 \\
\hline 57.81 & 57.76 & 28.10 & 45.85 & 68.85 & 68.53 \\
\hline 67.00 & 66.65 & 62.19 & 62.21 & 73.05 & 72.99 \\
\hline 70.33 & 70.18 & 71.01 & 70.71 & 62.62 & 62.37 \\
\hline 64.63 & 64.31 & 63.07 & 63.26 & 71.48 & 71.25 \\
\hline 56.09 & 55.97 & 71.61 & 71.38 & 76.61 & 77.06 \\
\hline 76.49 & 76.62 & 65.05 & 64.71 & 79.21 & 79.55 \\
\hline
\end{tabular}

Table 3: Selected land use/land cover categories

\begin{tabular}{|c|c|c|c|c|c|c|}
\hline No. & Year & Build Up Area & Forest & Residential & Industrial & Commercial \\
\hline 1 & 2003 & 6356.595 & 7.361 & 2802.5 & 77.552 & 620.625 \\
\hline 2 & 2002 & 6334.512 & 7.186 & 2792.691 & 77.280 & 618.079 \\
\hline 3 & 2000 & 6312.506 & 7.202 & 2782.917 & 77.010 & 615.916 \\
\hline 4 & 1997 & 6298.492 & 7.217 & 2776.739 & 76.839 & 614.549 \\
\hline 5 & 1990 & 5195.878 & 8.480 & 2290.531 & 63.385 & 506.9 \\
\hline
\end{tabular}

The build-up area reaching its highest capacity and forest area is at its lowest values. The data were generated from 1984 until 2001; however, only the years 1998 until 2006 will be considered for the purpose of this study in order to match corresponding WQI data available. The data was generated for build-up Area, forest area, residential area, commercial area and industrial area. 


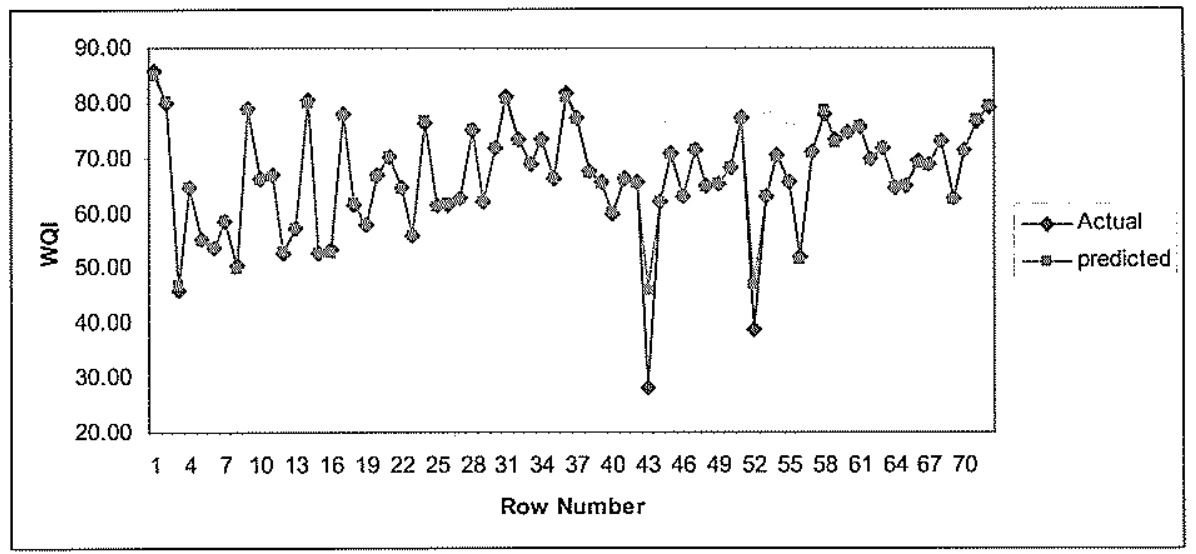

Figure 4: Time-Series Graph of Actual vs. Predicted WQI at Station 18 of Gombak River

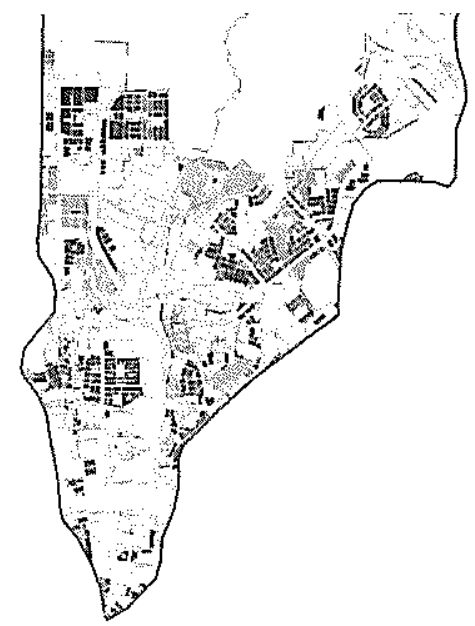

Figure 5: Land Use Map of Gombak River Watershed

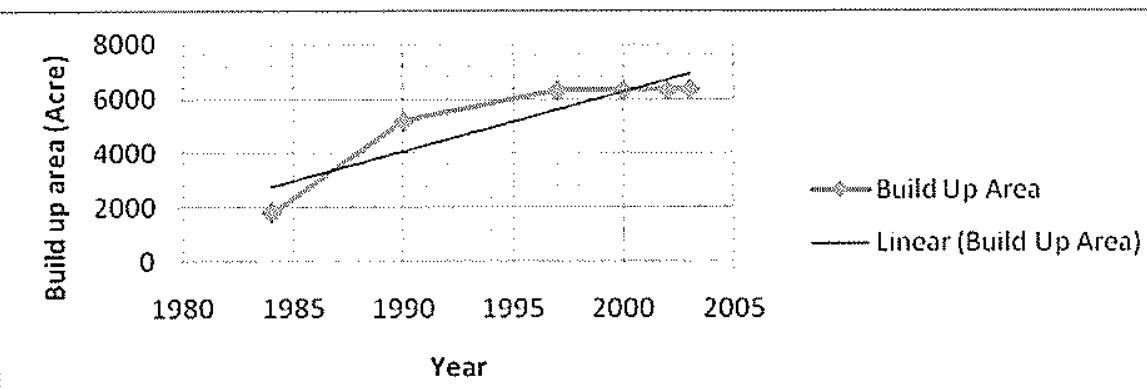

Figure 6: Build-Up Area of Station 18 from 1980 to 2005 


\section{Buildup Area Data Generation}

Using the 3rd degree Polynomial model: $\quad y=a+b x+c x^{2}+d x^{3} \ldots \ldots$

The initial curve for build up area as shown in Figure 7 was generated using the following coefficient data: $a=-7.312269 e+009, b=10961380$, $c=-5477.1702$ and $d=0.9122745$. The model operated with few numbers of data at the initial stage of generation and yielded a standard error of 49.54, and with correlation coefficient of 0.99985 .

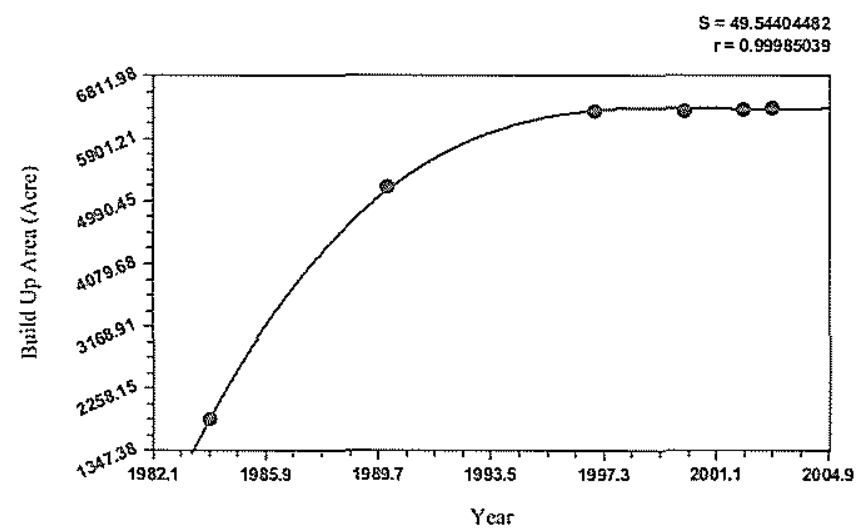

Figure 7: Data generation of Build-Up Area at Station 18 using Lagrange Model

Based on the data generated above, 4th Degree Polynomial model was used to generate the required build-up area from 1984 until 2010 on a monthly basis as shown in Figure 8. During the iteration process the following coefficient data were used: $a=-4.64034 \mathrm{e}+009, \mathrm{~b}=5692851.6, \mathrm{c}=-1582.5807$, $\mathrm{d}=-0.366894$, and $\mathrm{e}=0.00015750769$

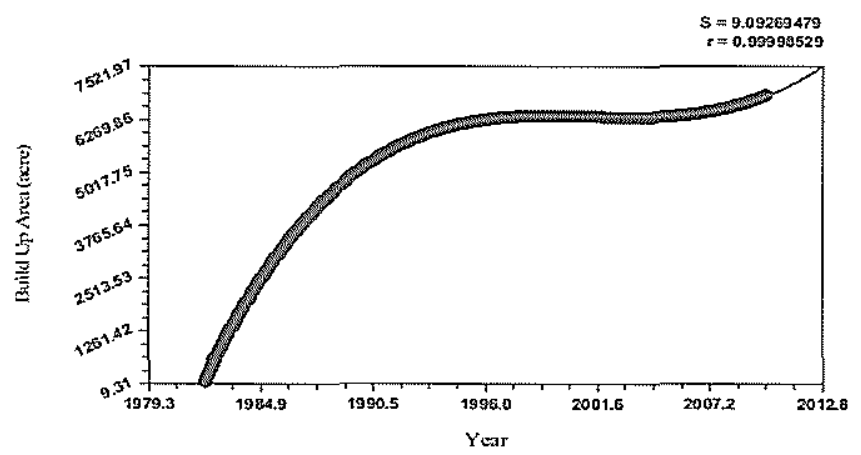

Figure 8: Build-Up Area Data Generation using $4^{\text {th }}$ Degree Polynomial Model 
The data exceeding the capacity of the watershed will not be considered as stated in the boundary condition of model applications.

\section{Forest Area Data Generation}

The forest area affecting station no. 18 of the watershed is decreasing in value; therefore a saturation growth-rate model was used to generate the area. To generate the initial data, the following coefficients were used: coefficient data: $a=0.11519198$ and $b=-1966.9875$ and were applied on the model:

$$
y=\frac{a x}{(b+x)}
$$

The initial curve (Figure 9) for data generated produced acceptable results; however due to few numbers of data, the curve needed adjustment. The second stage of data generation solved this problem and produced the required data.

Based on the initial saturation growth-rate model the remaining required data were generated from 1984 until 2010 using the same model (Figure 10) and applying new coefficient data for the model obtained from a number of iterations. The coefficient data were $a=0.11519245$, and $b=-1966.9874$. As the second application was based the first model the second application produced much lower standard error 0.0011342

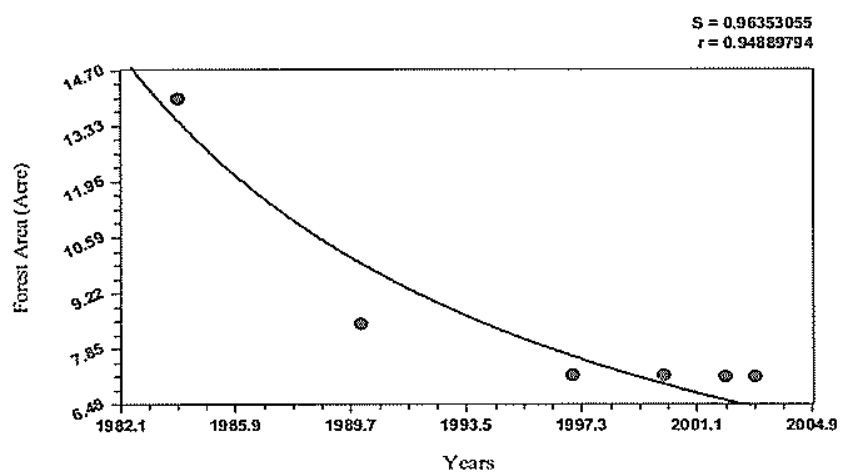

Figure 9: Forest Area Data Generation of Station 18 Using Therefore Saturation Growth-Rate Model 


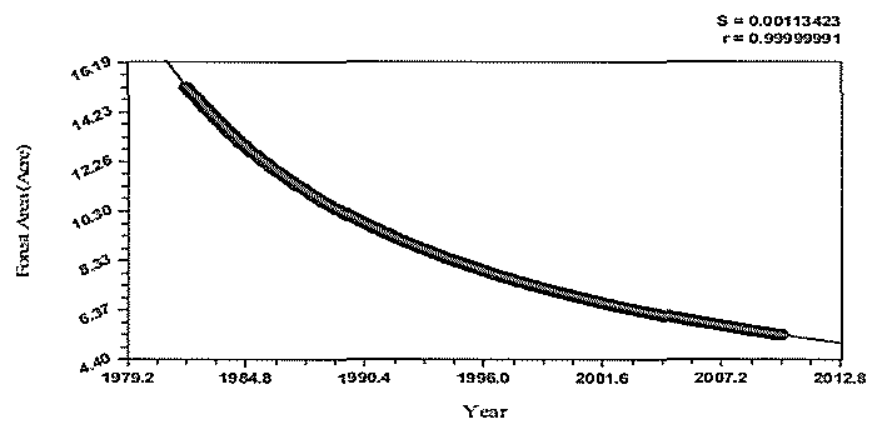

Figure 10: Application of Saturation Growth-Rate Model On Forest Area Affecting Station 18

\section{Data Generation of Residential Area Affecting Station 18}

Following the same method used for generating build-up area, the residential area was generated initially using 3 rd degree Polynomial model with coefficient data of $\mathrm{a}=-3.0076658 \mathrm{e}+009, \mathrm{~b}=4508008.2, \mathrm{c}=-2252.2557$, and $\mathrm{d}=0.37508435$ as shown in figure 5.50. The standard error was 20.913 in the initial model application. After the initial data were generated, the remaining required data were generated using 4th Degree Polynomial model with coefficient data of $a=-1.7159507 \mathrm{e}+009, \mathrm{~b}=1990074.4, \mathrm{c}=-413.14533, \mathrm{~d}=-$ 0.22143343 , and $\mathrm{e}=7.2490844 \mathrm{e}-005$. The residual curve gave better prediction ability with a standard error of 7.497584 as shown in Figure 11.

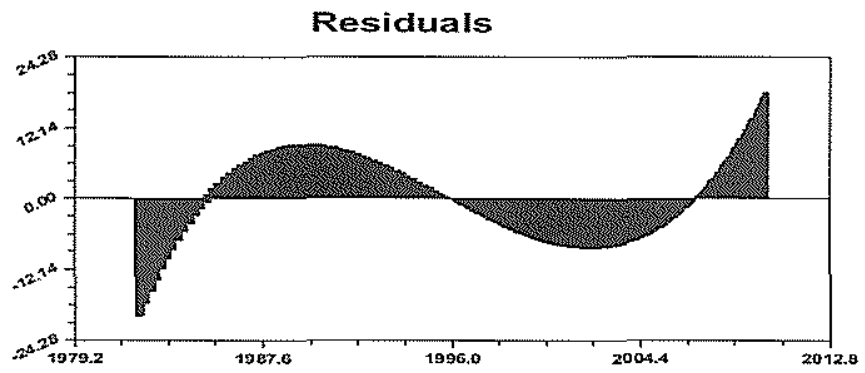

Figure 11: Residual Curve of Actual Versus Generated Data of Residential Area

\section{Data Generation for Commercial and Industrial Area Affecting Station 18}

Exponential model had been used for the generation of data for commercial and industrial area. The initial setup for data generation used $\mathrm{a}=7.3704247 \mathrm{e}-046$, and $b=0.055158363$ data coefficient for commercial area and for industrial 
area, $a=9.4973359 \mathrm{e}-047$, and $\mathrm{b}=0.055143224$. Data generated for commercial and industrial areas represented the years 1984 through 2010. For commercial area, the best standard error was 115.2054407, with Correlation Coefficient of 0.8126092 ; while industrial area had best standard error of 14.4130782 with correlation coefficient of 0.8122768 .

After data generation, exponential model was defined by new coefficient data of $\mathrm{a}=7.3720831 \mathrm{e}-046, \& \mathrm{~b}=0.05515825$ for commercial area, and $\mathrm{a}=$ $9.4985733 \mathrm{e}-047$ and $\mathrm{b}=0.055143159$ for industrial area for further data generation, forecast and analysis. The standard error for commercial and industrial area was 0.0869008 and 0.0108680 respectively.

\section{ANN Training of Gombak River LU/LC Parameters for Station 18}

A neural network was set up in order to train the generated LU/LC data affecting station 18 of Gombak River. The network architecture consisted of 5 hidden nodes, and 94 rows. The network which used pack propagation algorithm carried out 125500 cycles of iterations as described in the training boundary conditions. The average predicted water quality index during this period (9 years) was 66.68 . The normalized RMS error was $19.97 \%$ and actual error of 8.47. The high error value was expected at this part as the learning process is between a more stable LU/LC parameters and heterogeneous WQI that changes continuously. The network was able to identify a pattern while the training process continued. The pattern indicated that the WQI predicted based on LU/LC data was more linear than that of actual WQI as shown in figure time series of station 12 (Figure 12).

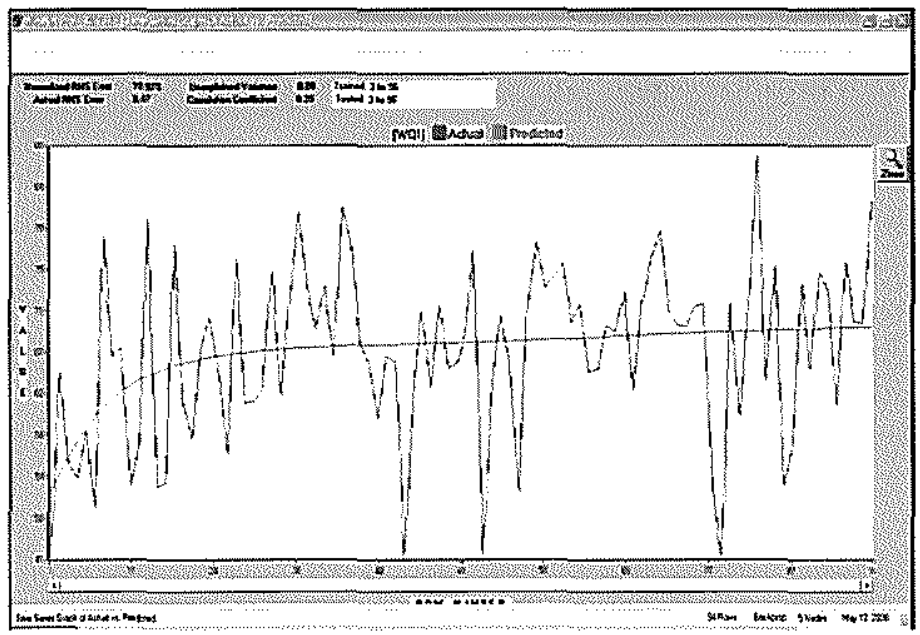

Figure 12: Time Series Graph of Actual vs. Predicted WQI at Station 18 
Faris Goroshi and Alias Abdullah

An Integrated Approach for the Prediction of Water Quality Index based on Land Use Atributes Using Data Generation Method and Back Propagation Network Algorithm

In order to predict the WQI using the LA-WQI the sub indices of selected LU/LC parameters had to be calculated. Using the method described previously in the research approach, the calculated sub indices were then multiplied by the weight factor of each category. follows:

The LA-WQI was then calculated using the proposed model equation as

$$
L A W Q I=100-\left[0.15 B U_{s i}+0.17 R s i+0.26 C s i+0.38 I s i+0.04 F s i\right]
$$

The results of predicted WQI obtained using LA-WQI, shows a continuous decrease of water quality index from 66.825 in 1998 to 64.677 in 2006. As the activities increase throughout the watershed the values of WQI quality decreases accordingly. The values of predicted WQI using the mentioned methods are illustrated in Figure 13.

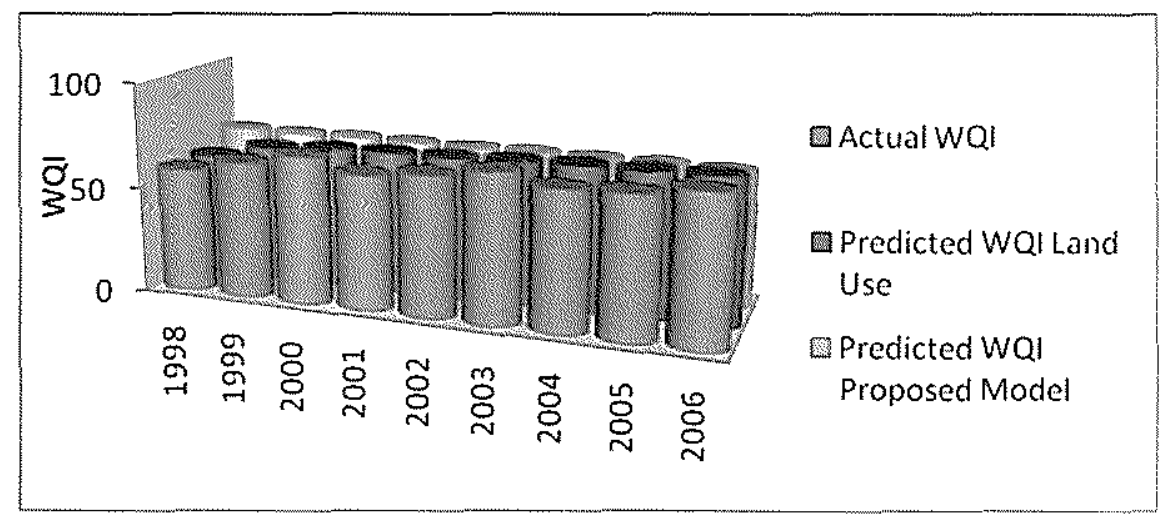

Figure 13: Values of WQI Obtained Using DOE-WQI, ANN-WQI and LA-WQI Models

The average mean results of WQI from each method were very near in value. The results showed an accuracy of $98 \%$ between Actual DOE WQI and LA WQI for station no. 18 of Gombak River.

As shown in Figure 14, average Values of WQI for Actual, ANN Predicted and LA WQI predicted are $66.299,66.844$ and 66.008 respectively which constitute an accuracy range of 97.9 to $99.5 \%$. 


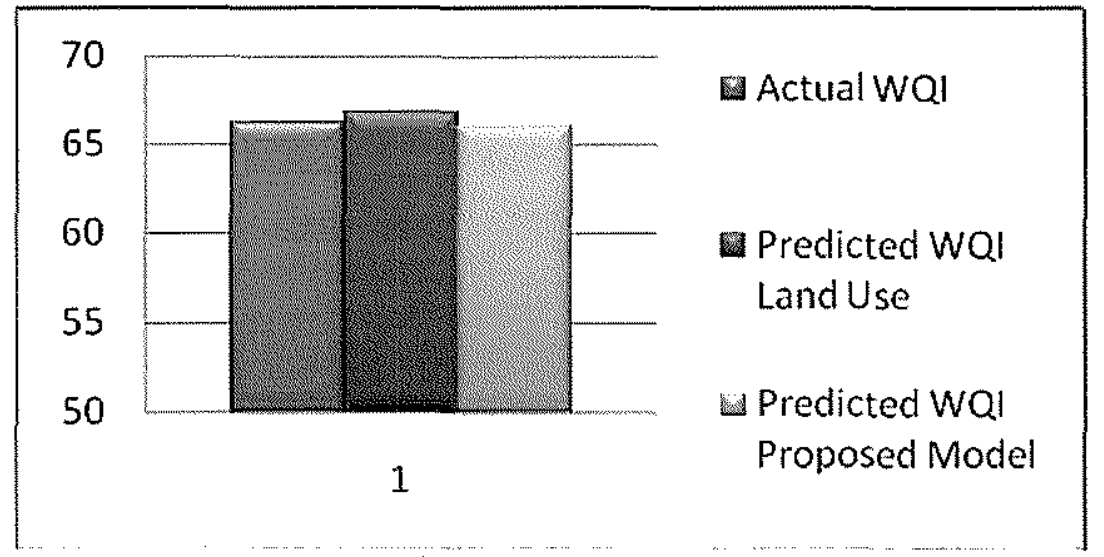

Figure 14: Average Values of WQI using DOE, ANN and LA-WQI Models

\section{VALIDATION}

In order to carry out a sensitivity test to validate the method for generating and forecasting LU/LC data, some of the obtained data were withheld and were not used in originating the models for data generation. These data represent LU/LC data for the year of 1984

The average area for the whole year was considered during the validation process, and it was compared to actual land use data for the same year as shown in Table 4. The land use area obtained using the method described in the methodology to generate and forecast data, had given a very high precision ranging from 91.862 to 95.902 when compared to actual data obtained from DOA.

Table 4: Comparison between Average Values of Actual vs. Predicted Data

\begin{tabular}{|c|c|c|c|c|}
\hline & BU (Acre) & R (Acre) & C (Acre) & I (Acre) \\
\hline Actual & 1984.43 & 1229.6 & 17.569 & 4.837 \\
\hline Average & 1899.234 & 1338.524 & 16.84918 & 4.621188 \\
\hline Accuracy \% & 95.706 & 91.862 & 95.902 & 95.538 \\
\hline
\end{tabular}

The trends which were chosen to describe the pattern of development were very realistic, and succeeded to mimic the actual patterns of development. Furthermore, and in order to see the pattern of deterioration of the water quality of the Gombak River with respect to the increase of land use within the watershed, the LA-WQI model was applied on three stations. The average values of WQI obtained on the three stations were taken from the same dates to 
ensure the consistency of the results as shown in Table 4. The sub-indices were multiplied by their respective factor explained previously. The Values of WQI were $96,91.9$ and 65.7 respectively.

\section{CONCLUSION}

This study had focused on finding a low-end alternative for water quality monitoring techniques. It used data generation method coupled with ANN approach to provide an effective prediction model that suits environments with high heterogeneity. The proposed approach minimized most of anomalies associated with prediction methods and provided water quality forecasting and prediction with high accuracy. The study proposed a method that mimicked the actual development pattern in the watershed; however, it is recommended that for future planning, watershed development should follow an identified model fit for development. All developmental schemes should be conducted in accordance with a specific allocation of time and space which follows a certain model. This will help in producing more accurate forecasting of LU/LC subindices, which in turn will help in forecasting the WQI for the future years until the watershed is fully developed. After the watershed is fully developed, the activities of different categories of land use will produce a uniform discharge of effluents to the river. The study had also identified that the mid streams of Gombak River is deteriorating in quality due to rapid development within the vicinity of the watershed. Despite the high accuracy attained by the application of LA-WQI model on Gombak River; it has not yet been tested in other rivers due to the limitation of the scope of this study. It is recommended that future studies should be able to further test the current model on a regional scale.

\section{REFERENCES:}

\section{Books/Journals:}

Alias Abdullah, Kazuhisa Iki, and Mitsuo Morozumi, 1994. A study to evaluate change of zoning in GIS operation due to the diversification of the AHP judgment, Proceeding of the Sixteenth Symposium on Computer Technology of Information, System and Applications, AlJ, S-5-6, pp.349354.

Alias Abdullah, Kazuhisa Iki, and Mitsuo Morozumi, 1994. An integrated approach of AHP and GIS application to analyze and develop recreational zoning, Journal of architecture planning and Environmental Engineering, AIJ, No. 463, pp. 213-222. 
Bishop, J. E., 1973. Limnology of a Small Malayan River, Sungai Gombak, The Hague. pp. 485.

Carr, G.M. and Chambers, P.A., 1998. Spatial and temporal patterns of nutrients and algal abundance in Alberta rivers. Report prepared for the Prairie Provinces Water Board, Regina, SK.

Chandra Sekhar, M. and Anand Raj, P., 1995. Land Use Water Quality Modeling, Journal Of Water Science Technology, Vol. 31, No. 8, IWA Publishing, pp.383-386.

Correll, D.L., Jordan, T.E., and Weller, D.E., 2001. Effects of precipitation, air temperature, and land use on organic carbon discharges from Rhode River watersheds. Water, Air, and Soil Pollution, 128, pp. 139-159.

Diane M. L., David P. A., 2004. Use of Artificial Neural Network Models to Predict Indicator Organisms Concentrations in an Urban Watershed, AGU, 85(17), Joint Assembly Suppl., Abstract H53A-06 1330h POSTER Engel, B. R., Srinivasan, R., Arnold,J., Rewerts,C., and Brown, S. J., 1993. Nonpoint Source (NPS) Pollution Modelling Using Models Integrated with Geographic Information Systems (GIS). Water Science and Technology, Vol. 28, No. 3-5, pp. 685-690.

Evans, B. M. and Miller, D. A., 1988. Modeling Nonpoint Pollution at the Watershed Level with the Aid of a Geographic Information System. In: Nonpoint Pollution: 1988 - Policy, Economy, Management, and Appropriate Technology. American Water Resources Association, pp. 283-290.

Faris, F.G. and Alias Abdullah, 2008. A Study on the Water Quality of Gombak River Using Artificial Neural Network, Al-Rissala Journal, International Islamic University Malaysia 2008 (In press).

Faris, F.G. and Alias Abdullah, 2008. Prediction of Water Quality Index Using Back Propagation Network Algorithm. Case Study: Gombak River, Journal of Engineering Science and Technology, 2008 (In press).

Goodchild, M. F., Parks, B. O., and Steyaert, L. T., (eds.), 1993. Geographic Information Systems and Environmental Modeling, Oxford University Press, New York, pp. 231-237.

Hafizan Juahir, Sharifuddin M. Zain, Zainal Ahmad, Nazari M. Jaafar, 2004. An Application of Second Order Neural Network Back Propagation Method in Modeling River Discharge. In Water Environmental Planning: Towards Integrated Planning and Management of Water Resources for Environmental Risks, Alias Abdullah, Norio Okada, and Mohd Kamil Yusoff, eds., International Islamic University Malaysia, pp. $307-324$.

Hubert-Moy, L., Cotonnec, A., Le Du, L., Chardin, A., and Perez, P., (eds.), 2001. A Comparison of Classification Procedures of Remote Sensed Data Applied on Different Landscape Units, Remote Sensing of the Environment, Elsevier, Vol. 75, no. 2, pp. 174-187. 
Junaida Ariffin, Aminuddin Abdul Ghani, Nor Azazi Zakaria, and Ahmad Shukri Yahya, 2004. Sediment Prediction Using ANN and Regression Approach, $I^{\text {st }}$ International Conference on Managing Rivers in the $2 I^{\text {st }}$ Century: Issues \& Challenges, Malaysia pp. 168-174.

Kadri, Yurekli, Ahmet Kurunc, and Huseyin Simsek, 2004. Prediction of daily

Stream Flow Based on Stochastic Approaches, Journal of Spatial Hydrology, Vol. 4 No. 2.

Kamarul Ismail, and Ruslan Rainis, 2004. Modeling River Water Quality Index Using Artificial Neural Networks and Geographical Information System,

In Water Environmental Planning: Towards Integrated Planning and Management of Water Resources for Environmental Risks, Alias Abdullah, Norio Okada, and Mohd Kamil Yusoff, eds., International Islamic University Malaysia.

Lai, F.S., 1983. Biochemical Oxygen Demand Concentration of Two River Basins of Selangor, Pertanika. Vol. 6(3), pp. 32-43.

Loke, E., Warnaars E. A., Jacobsen P., Nelen F. and Ceu Almeida M., 1997.

Artificial Neural Networks as a tool in Urban Storm Drainage, Journal of Water Science and Technology, Vol. 36, Issues 8-9, pp. 101-109.

Noorazuan M. H, Ruslan Rainis, Hafizan Huahir, Sharifuddin, M. Zain, and Nazari Jaafar, 2003. GIS Application in Evaluating Land use - Land Cover Change and its Impact on the Hydrological Regime in Langat River Basin, Malaysia, Map Asia Conference 2003, GISdevelopment.net Picton, P. D., 1994. Introduction to neural network, the Macmillan press Itd, London.

Rounds, S.A., 2002. Development of a Neural Network Model for Dissolved Oxygen in the Tualatin River, Oregon, Proceeding of the second Federal Interagency Hydrologic Modeling Conference, Las Vegas, Nevada, July 29 - August 1, 2002 Subcommittee on Hydrology of the interagency Advisory Committee on Water Resources.

Ruslan Rainis, 2003. Application of GIS and Landscape Metrics in Monitoring Urban Land Use Change, "Urban Ecosystem Studies in Malaysia. A Study of Change", Noorazuan Md Hashim \& Ruslan Rainis, eds., Universal Publishers, pp 267-278

Sekhar M. Chandra, and Sreenivasulu, 2003. Modeling Nutrients Contributed by Overland Flow From the Krishna River Basin, Diffuse Pollution Conference. Dublin, Water Resources Management, 1A, pp. 20-23.

Smith, A. J., Goetz, S.D., Prince, R. and Wright, B., 2003. Estimation of subpixel impervious surface area using a decision tree approach, Remote sensing of the environment. (in press).

Tong, S. T. Y. and Chen, W., 2002. Modeling the relationship between land use and surface water quality. Journal of Environmental Management, 66: pp. 377-393. 
Wang, X., 2001. Integrating water-Quality management and Landuse Planning In a Watershed Context. Journal of environmental management, 61, pp. 25-36.

Watts, R.L., 1966. New Federations: Experiments in the Commonwealth. Oxford: Clarendon Press.

Wenwei Ren, Yang Zhong, Meligrana, J., Anderson, B., Watt, W.E., Jiakuan Chen, and Hok-Lin Leung, 2003. Urbanization, Land use, and Water Quality in Shanghai, Environment International, 29, Elsevier, pp. 649659

Yusoff, M.K., Heng, S.S., Majid, N.M., Mokhtaruddin, A.M., Hanum, I.F., Alias, M.A, Kobayashi, S., 2001. Effects of different land use patterns on the stream water quality in Pasoh, Negeri Sembilan, Malaysia. In Rehabilitation of Degraded Tropical Forest Ecosystems: Workshop Proceedings, Kobayashi, S., Turnbull, J.W., Toma, T. Mori, T., Majid, N.M.N.A. eds., 2-4 November 1999, CIFOR, Bogor, Indonesia, pp. 8798.

Zou, R., Lung, W.S., and Guo, H., 2002. Neural Network Embedded Monte Carlo Approach for Water Quality Modeling Under Input Information Uncertainty. Journal of Computing in Civil Engineering, ASCE, 16 (2), pp. $135-142$.

\section{Internet:}

Cormac Technologies Inc. 1999. Manual, NeuNet Pro, Revision 2.2. Cormac Technologies Inc. <http://www.cormactech.com/Neunet>

Dixon, B., 2004. Applicability of Neuro-Fuzzy Techniques In Predicting Ground Water Vulnerability: A GIS-based sensitivity analysis. Journal of Hydrology, published by Elsevier B. V. doi:10.1016/jhydrol.2004.11.010. Retrieved online on 22/04/2005. <http://www.sciencedirect.com> 
